\title{
Facile Preparation and Dye Adsorption Performance of Poly(N-isopropylacrylamide-co-acrylic acid)/Molybdenum Disulfide Composite Hydrogels
}

\author{
Jianping Yang,* Kailun Wang, Zhengxiang Lv, Wenjun Li, Keming Luo, and Zheng Cao* \\ Cite This: ACS Omega 2021, 6, 28285-28296 \\ Read Online
}

ABSTRACT: Using $N$-isopropylacrylamide (NIPAM) and acrylic acid (AAc) as monomers, $N, N^{\prime}$-methylenebisacrylamide (MBA) as a cross-linking agent, and molybdenum disulfide $\left(\mathrm{MoS}_{2}\right)$ as functional particles, a $\mathrm{P}(\mathrm{NIPAM}-\mathrm{co}$ AAc) $/ \mathrm{MoS}_{2}$ composite hydrogel was prepared by free radical polymerization initiated by ultraviolet light. The results of Fourier transform infrared spectroscopy, Raman spectroscopy, and scanning electron microscopy show that $\mathrm{MoS}_{2}$ has been successfully introduced into the P(NIPAM-co-AAc) system, and the obtained composite hydrogel has a porous network structure. Studies on the swelling property and dye adsorption performance show that the addition of $\mathrm{MoS}_{2}$ can increase the swelling ratio of $\mathrm{P}$ (NIPAM-co-AAc) hydrogels to a certain extent and can significantly improve the ability of the $\mathrm{P}$ (NIPAM-co-AAc) hydrogel to adsorb methylene blue (MB). The adsorption process of $\mathrm{MB}$ by the composite hydrogels conforms to the pseudo-second-


order kinetics and the Langmuir isotherm adsorption models. The estimated equilibrium adsorption capacity $\left(Q_{\mathrm{m}}\right)$ using the Langmuir isotherm model can reach $1258 \mathrm{mg} / \mathrm{g}$, mainly due to the electrostatic interaction between the negatively charged groups $-\mathrm{COO}^{-}$and $\mathrm{MoS}_{2}$ particles on the network structure and the positively charged dye MB. The adsorption of MB by $\mathrm{P}\left(\mathrm{NIPAM}-\mathrm{Co}^{-}\right.$ $\mathrm{AAc}) / \mathrm{MoS}_{2}$ composite hydrogels depends on the temperature during adsorption. Compared with room temperature, a high temperature of $40{ }^{\circ} \mathrm{C}$ above the poly $\left(\mathrm{N}\right.$-isopropylacrylamide) (PNIPAM) phase transition temperature ( $\left.\sim 32{ }^{\circ} \mathrm{C}\right)$ leads to a decreased adsorption capacity of the $\mathrm{P}(\mathrm{NIPAM}-\mathrm{co}-\mathrm{AAc}) / \mathrm{MoS}_{2}$ composite hydrogel for MB due to the enhanced hydrophobic properties of the network structure and the decrease of the swelling ratio. The prepared hydrogel material can be used as a good adsorbent for dyes, which is promising in wastewater treatment.

\section{INTRODUCTION}

The discharge of dye-containing wastewater in various countries in the world is increasing. Once the water body is polluted, it is not easy to restore to the expected original state quickly. ${ }^{1,2}$ At present, adsorption technology is considered by environmental researchers to be the most effective and promising method for sewage treatment. ${ }^{3}$ Therefore, it is essential to develop an economical and efficient material for adsorbing harmful substances. The adsorption materials that have been reported are organic and inorganic materials, including poly $\left(4,4^{\prime}\right.$-diaminodiphenylmethane $){ }^{4}$ polyelectrolyte multilayers, ${ }^{5}$ polyaniline and polypyrrole macro-/nanoparticles, ${ }^{6}$ sodium titanate, ${ }^{7} \mathrm{CoMo}_{4},{ }^{8}$ sandwichlike magnesium silicate/reduced graphene oxide nanocomposite, ${ }^{9}$ activated carbon, ${ }^{10}$ and carbon nanotubes. ${ }^{11}$ However, the adsorption materials that have been reported so far also have many shortcomings, such as complex preparation processes, use of toxic and hazardous substances, poor stability, and weak adsorption capacity.

Hydrogel is a polymer network with a three-dimensional structure that is porous and has a large surface area and many channels. Because of the presence of hydrophilic groups such as hydroxyl, carboxylic acid, amide, and sulfonic acid groups in the polymer forming the hydrogel structure, the hydrogel has an affinity for water, swells in water but does not dissolve, and can absorb a large amount of water. $\operatorname{Poly}(N$-isopropylacrylamide) (PNIPAM) hydrogels are temperature-sensitive and are a type of intelligent hydrogels that have been studied extensively. The temperature response is corresponding to a discontinuous volume phase change, which can be found near $32{ }^{\circ} \mathrm{C} .{ }^{12-14}$

Copolymerization of NIPAM and acrylic acid (AAc) can lead to a copolymer P(NIPAM-co-AAc), which can form a chelate with various metal ions to achieve good adsorption performance due to the presence of the AAc units containing

Received: August 16, 2021

Accepted: October 5, 2021

Published: October 15, 2021 


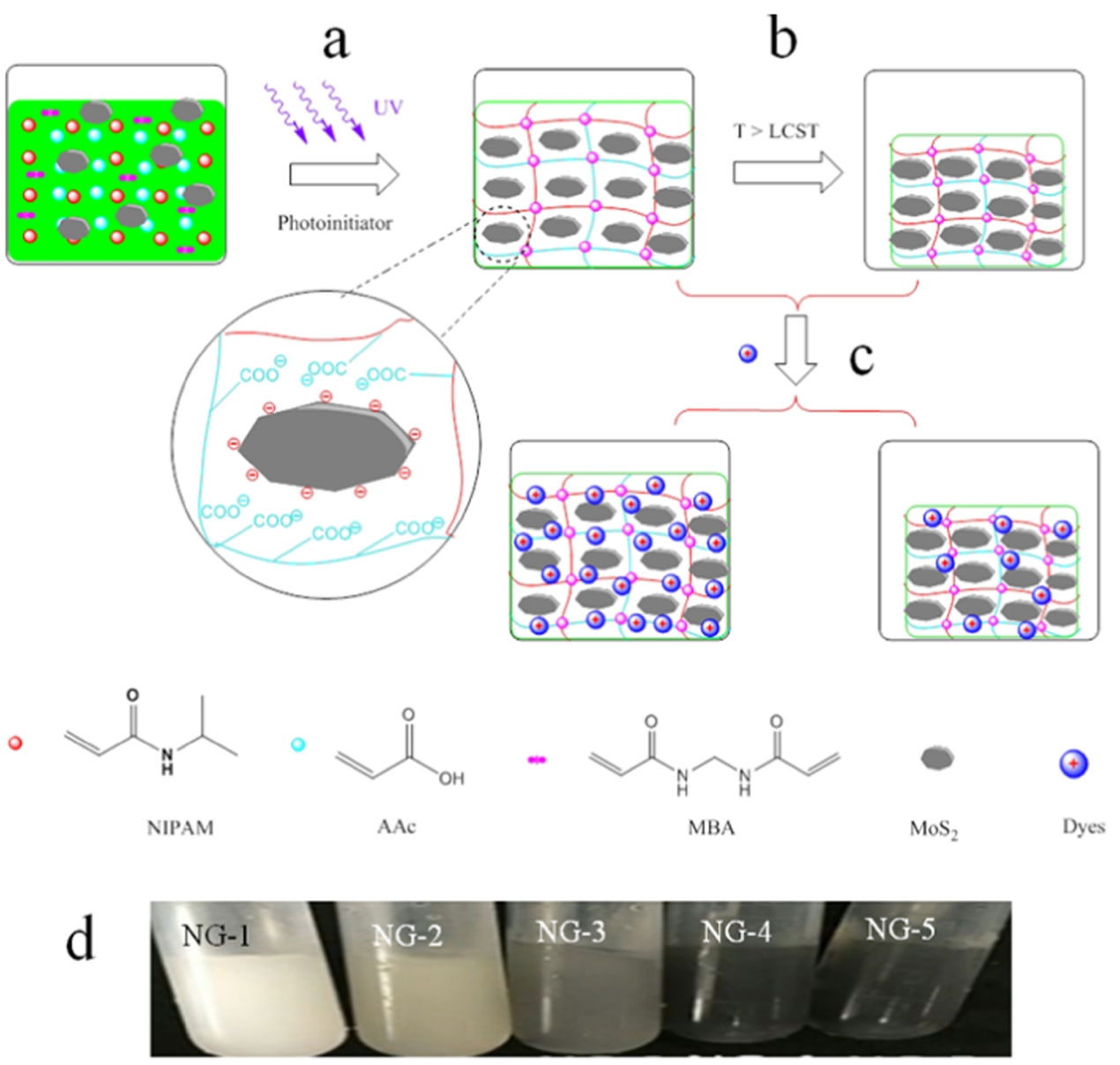

Figure 1. Formation of $\mathrm{P}(\mathrm{NIPAM}-\mathrm{co}-\mathrm{AAc}) / \mathrm{MoS}_{2}$ composite hydrogels (a); temperature volume phase transition of hydrogels (b); dye adsorption behavior of hydrogels (c); and the appearance of the obtained composite hydrogels containing different contents of $\mathrm{MoS}_{2}(\mathrm{~d})$.

ionizable and hydrophilic carboxyl groups and its function as an excellent chelating group. The obtained composite hydrogel can have better swelling, adsorption, $\mathrm{pH}$ response, and other properties. $^{15-20}$ For example, Kureha et al. ${ }^{21}$ studied the structural changes of $\mathrm{P}(\mathrm{NIPAM}-\mathrm{co}-\mathrm{AAc})$ microgels and found that the hydrophobic and electrostatic interactions between cationic dye molecules and anionic microgels affected the separation of microgels and phase transition behavior. Compared with other adsorption materials, the hydrogel has good biocompatibility, environmental friendliness, higher adsorption rate, adsorption capacity, and is easy to prepare. As a fast response and high-capacity adsorption material, the hydrogel has become an important material for removing heavy metals, ${ }^{22,23}$ herbicides, ${ }^{24}$ organic dyes, ${ }^{25}$ and many other pollutants from aqueous media.

The hydrogel has a large surface area and numerous channels inside, providing adsorption sites, and can be used as an ideal material for adsorbing dye molecules. However, a single hydrogel has low strength and low adsorption capacity. Introducing functional components, ${ }^{26}$ loading with a certain amount of inorganic nanoparticles, ${ }^{27,28}$ and designing a double cross-linked network structure ${ }^{29}$ can greatly improve the mechanical properties, adsorption capacity, environmental stimulus-response performance, and stability of the hydrogels. $^{30-35}$ Inorganic nanoparticles have unique properties in mechanical, electrical, magnetic, thermal, optical, and chemical activities due to their unique volume effect, surface effect, quantum size effect, and macroscopic quantum tunneling effect. Recently, with the development of nanoscience and nanotechnology, nanomaterials have great potential to solve environmental problems. ${ }^{36-38}$ Compared with traditional materials, nanostructured materials have a higher surface area and show higher adsorption efficiency and faster adsorption rate in water treatment. In addition, nanomaterials also have the following characteristics: they have high adsorption performance, are not harmful to the environment, and can be easily recycled from the environment. In the hydrogel system, the introduction of nanomaterials, including graphene oxide, ${ }^{39,40} \mathrm{Fe}_{3} \mathrm{O}_{4},{ }^{41,42}$ manganese oxide $\left(\mathrm{MnO}_{2}\right)$, ${ }^{43}$ titanium oxide $\left(\mathrm{TiO}_{2}\right),{ }^{44,45}$ and zinc oxide $(\mathrm{ZnO}),{ }^{46}$ to prepare composite hydrogels plays an increasingly important role in the wastewater treatment process. Nanomaterials can be successfully used as efficient, economical, and environmentally friendly adsorbents to remove various toxic substrates in wastewater, such as heavy metals and azo dyes. Zhao et al. ${ }^{47}$ prepared a three-dimensional hemin-functionalized graphene hydrogel $(\mathrm{Hem} / \mathrm{GH})$ by a simple self-assembly method, which showed good mechanical strength and a high adsorption capacity of $341 \mathrm{mg} \mathrm{g}^{-1}$ for rhodamine $\mathrm{B}(\mathrm{RhB})$. The abovereported research work provides a new way for preparing hydrogel materials with high dye adsorption capacity and excellent mechanical properties. However, it is still necessary to explore new inorganic nanomaterials to prepare composite hydrogels with low cost and high adsorption capacity, which is helpful for sewage purification and environmental protection. 
Two-dimensional layered molybdenum disulfide $\left(\mathrm{MoS}_{2}\right)$ is composed of a single layer or a few layers of $\mathrm{MoS}_{2}$. It is a twodimensional nanomaterial with a sheet structure similar to the carbon material graphene. It has become a research hotspot in the field of emerging materials due to its excellent optoelectronic properties. ${ }^{48-51}$ Schneider et al. ${ }^{52}$ prepared poly(lactic acid) (PLA) by solution blow spinning (SBS) technology and then modified by spraying with $\mathrm{MoS}_{2}$ to obtain the PLA/ $\mathrm{MoS}_{2}$ nanocomposite. The results show that the $\mathrm{MoS}_{2}$ nanoflakes used to alter the sub-micrometer fibers achieve an adsorption capacity of $111.2 \mathrm{mg} \mathrm{g}^{-1}$ for methylene blue (MB). The high adsorption capacity of $\mathrm{MoS}_{2}$ combined with the interconnected pores of the fiber membrane and simple modification strategies make PLA/ $\mathrm{MoS}_{2}$ fiber composite materials particularly suitable for high-performance adsorption membranes. This study by Tian et al. ${ }^{53}$ shows that the use of $\mathrm{MoS}_{2} / \mathrm{CuS}$ nanosheet composites (NCs) as adsorbents can quickly and effectively remove different dyes in wastewater. $\mathrm{MoS}_{2} / \mathrm{CuS} \mathrm{NCs}$ are prepared by a simple hydrothermal route. The adsorption capacity of the composite material for rhodamine B ( $\mathrm{RhB})$, methylene blue (MB), methyl orange (MO), and rhodamine 6G dyes (RhB 6G) is $273.23,432.68,98.78$, and $211.18 \mathrm{mg} / \mathrm{g}$, respectively. This is due to its high specific surface area $\left(106.27 \mathrm{~m}^{2} / \mathrm{g}\right)$ and small mesopores $(2.3 \mathrm{~nm})$, providing numerous adsorption sites and uniform coverage for dye molecules. Based on the unique volume effect and surface effect of nanomaterials, when nanoparticles are introduced into the hydrogel to form composite materials, the nanoparticles can maintain their original characteristics and adjust the physical and chemical properties of the nanocomposite hydrogel materials in a variety of ways. For example, changing the amount of nanoparticles can make the comprehensive performance of the nanocomposite better than each single component and even obtain some new properties to meet the application requirements of high-capacity dye adsorption.

In this study, the $\mathrm{P}(\mathrm{NIPAM}-\mathrm{co}-\mathrm{AAc}) / \mathrm{MoS}_{2}$ composite hydrogel was prepared by free radical polymerization of NIPAM and AAc initiated by ultraviolet light. The influence of adsorption temperature, $\mathrm{MoS}_{2}$ loading content, and other factors on the structure and performance of hydrogels was studied. The synthesis of the composite hydrogel containing $\mathrm{MoS}_{2}$ is simple, its adsorption capacity for $\mathrm{MB}$ is high, and it can be more effectively used in water treatment for the removal of dyes.

\section{RESULTS AND DISCUSSION}

Figure 1 shows the formation reaction process of the $\mathrm{P}$ (NIPAM-co-AAc)/ $\mathrm{MoS}_{2}$ composite hydrogel prepared in this work: the temperature phase transition of the hydrogel, the dye adsorption behavior of the hydrogels, and the appearance of the prepared hydrogels. As shown in Figure 1a, NIPAM and AAc were used as monomers, and the photoinitiator 2960 was used to initiate the polymerization and cross-linking reaction of the monomers by ultraviolet light irradiation. In the presence of $\mathrm{MoS}_{2}$ particles, the $\mathrm{P}(\mathrm{NIPAM}-\mathrm{co}-\mathrm{AAc}) / \mathrm{MoS}_{2}$ composite hydrogel was obtained. The introduction of the NIPAM unit endows the composite hydrogel with temperature-responsive properties. The effects of different temperatures on the threedimensional cross-linked network structure and swelling and shrinkage properties of the composite hydrogel can be studied. As shown in Figure $1 \mathrm{~b}$, the composite hydrogel undergoes a volume phase transition at $40{ }^{\circ} \mathrm{C}$ above the phase transition temperature. Because AAc contains a carboxylic group, it has a negative charge and can interact with positively charged dye molecules in water in the next step. $\mathrm{MoS}_{2}$ particles are a kind of flake-shaped granular material, which can take advantage of its superior size and surface effect and combine with AAc to improve the adsorption capacity of dyes. Figure 1c shows the dye adsorption behavior at room temperature and $40{ }^{\circ} \mathrm{C}$.

By controlling the content of $\mathrm{MoS}_{2}$ inorganic particles, five groups of hydrogels were prepared by free radical copolymerization in this experiment. Table 1 shows the formula and

Table 1. Formula and Appearance of P(NIPAM-co-AAc)/ $\mathrm{MoS}_{2}$ Composite Hydrogels

\begin{tabular}{lccccccc}
$\begin{array}{c}\text { label } \\
\text { name }\end{array}$ & $\begin{array}{c}\text { NIPAM } \\
(\mathrm{g})\end{array}$ & $\begin{array}{c}\mathrm{AAc} \\
(\mathrm{g})\end{array}$ & $\begin{array}{c}\mathrm{MBA} \\
(\mathrm{mg})\end{array}$ & $\begin{array}{c}2960 \\
(\mathrm{~g})\end{array}$ & $\begin{array}{c}\mathrm{MoS}_{2} \\
(\mathrm{mg})\end{array}$ & $\begin{array}{c}\mathrm{H}_{2} \mathrm{O} \\
(\mathrm{mL})\end{array}$ & appearance \\
$\mathrm{NG}-1$ & 1 & 0.1 & 2.72 & 0.02 & 0 & 6 & white \\
$\mathrm{NG}-2$ & 1 & 0.1 & 2.72 & 0.02 & 1 & 6 & gray \\
$\mathrm{NG}-3$ & 1 & 0.1 & 2.72 & 0.02 & 5 & 6 & dark \\
$\mathrm{NG}-4$ & 1 & 0.1 & 2.72 & 0.02 & 10 & 6 & black \\
NG-5 & 1 & 0.1 & 2.72 & 0.02 & 25 & 6 & black \\
\hline
\end{tabular}

product information of the $\mathrm{P}$ (NIPAM-co-AAc)/ $\mathrm{MoS}_{2}$ composite hydrogels, and their appearance is shown in Figure $1 \mathrm{~d}$. Among them, NG-1 is the blank control sample P(NIPAM-coAAc) hydrogel without added $\mathrm{MoS}_{2}$. In addition, NG-2, NG-3, NG-4, and NG-5 are P(NIPAM-co-AAc)/ $\mathrm{MoS}_{2}$ composite hydrogels with different $\mathrm{MoS}_{2}$ loading amounts, including 1, 5, 10 , and $25 \mathrm{mg}$, accounting for $0.1,0.5,1$, and $2.5 \%$ of the NIPAM content, respectively. It can be seen from Table 1 and Figure $1 \mathrm{~d}$ that the appearance of the hydrogel without added $\mathrm{MoS}_{2}$ in NG-1 is white. As the amount of added $\mathrm{MoS}_{2}$ increases, the color of the prepared hydrogel becomes darker and gradually turns black from gray. This is because as $\mathrm{MoS}_{2}$ particles appear black, they make the hydrogel appear black. In the next step, a series of tests and characterization will be conducted on the synthesized hydrogel to study its composition, swelling, and dye adsorption properties.

Figure 2 shows Fourier transform infrared (FT-IR) and Raman spectra of P(NIPAM-co-AAc) and P(NIPAM-co-AAc)/ $\mathrm{MoS}_{2}$ composite hydrogels. As seen in Figure 2a, there are two strong absorbance bands located at 3440 and $1640 \mathrm{~cm}^{-1}$, corresponding to the stretching vibration of $\mathrm{OH}$ in $\mathrm{AAc}$ and $\mathrm{NH}$ in NIPAM, and the stretching vibration of $\mathrm{C}=\mathrm{O}$ in $\mathrm{AAc}$ and NIPAM, ${ }^{54}$ respectively. The characteristic absorbance of the two peaks at 1380 and $1108 \mathrm{~cm}^{-1}$ is assigned to the stretching vibration of $\mathrm{CO}$ in AAc, indicating that the composite hydrogel containing monomer units including NIPAM and AAc was successfully synthesized. According to the infrared spectra of $\mathrm{P}(\mathrm{NIPAM}-\mathrm{co}-\mathrm{AAc}) / \mathrm{MoS}_{2}$ composite hydrogels with different contents of $\mathrm{MoS}_{2}$, it can be seen that the characteristic absorbance bands of the P(NIPAM-co-AAc) hydrogel also appears at around 3437 and $1636 \mathrm{~cm}^{-1}$. Since the FT-IR spectra were usually used for qualitative analysis, it is impossible to confirm whether there is any introduction of inorganic $\mathrm{MoS}_{2}$ particles in the P(NIPAM-co-AAc) hydrogel. Therefore, in the following analysis, Raman spectroscopy was used to determine the presence of $\mathrm{MoS}_{2}$.

Figure $2 \mathrm{~b}$ shows the Raman spectra of $\mathrm{MoS}_{2}, \mathrm{P}(\mathrm{NIPAM}-\mathrm{co}$ AAc) hydrogels, and $\mathrm{P}(\mathrm{NIPAM}-\mathrm{co}-\mathrm{AAc}) / \mathrm{MoS}_{2}$ composite hydrogels. In the Raman spectrum of $\mathrm{MoS}_{2}$, it was found that there are two strong characteristic peaks at about 403 and $374 \mathrm{~cm}^{-1}$, which are attributed to the out-of-plane vibration 

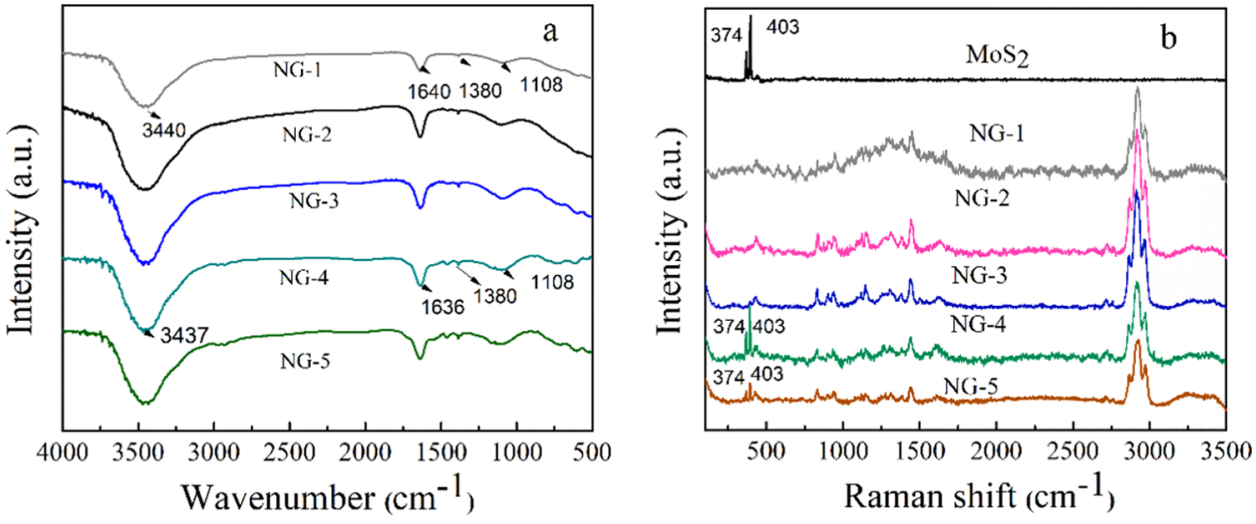

Figure 2. (a) FT-IR and (b) Raman spectra of $\mathrm{P}(\mathrm{NIPAM}-\mathrm{co}-\mathrm{AAc})$ and $\mathrm{P}(\mathrm{NIPAM}-\mathrm{co}-\mathrm{AAc}) / \mathrm{MoS}_{2}$ composite hydrogels.
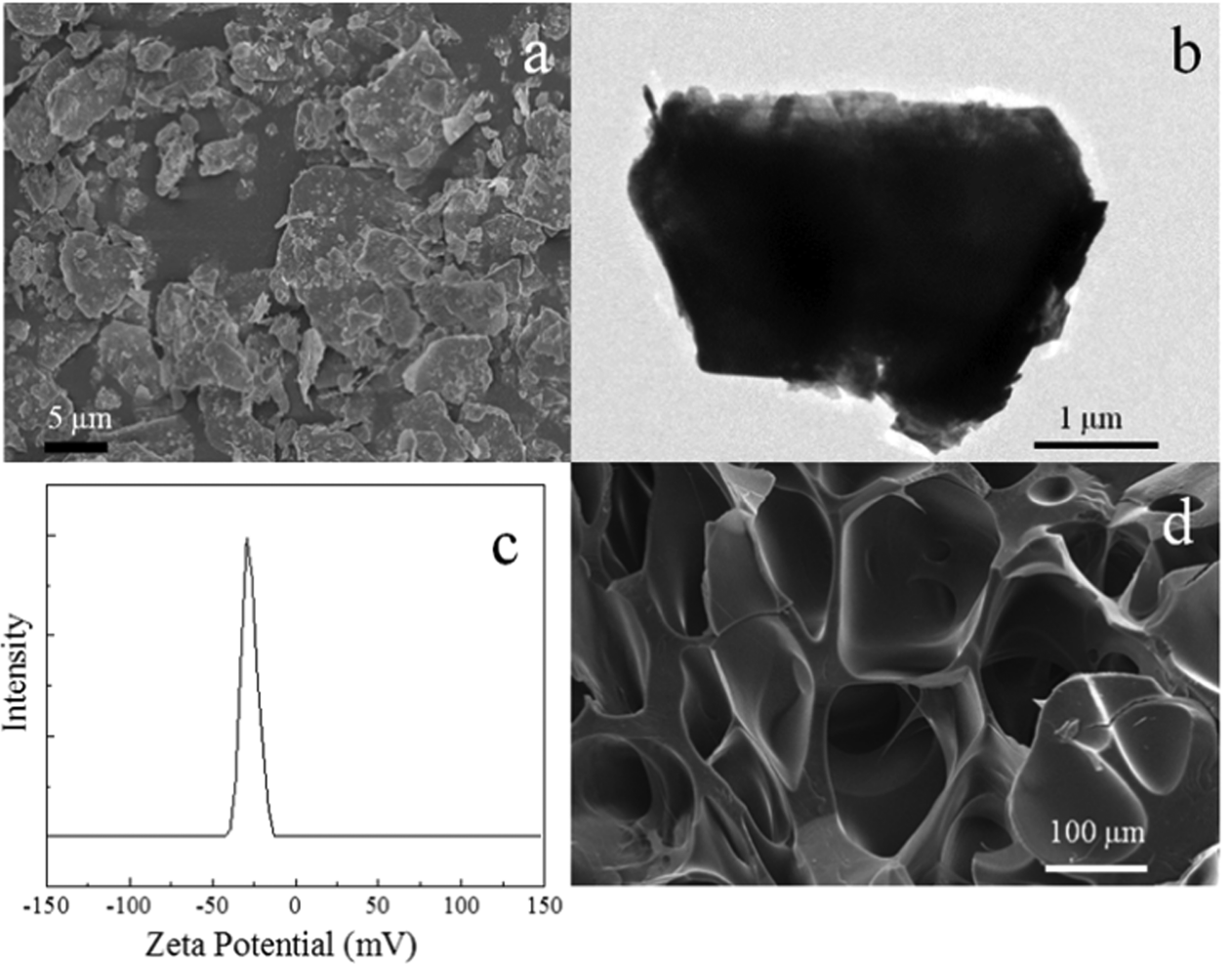

Figure 3. SEM (a) and TEM (b) images; the $\zeta$-potential distribution (c) of $\mathrm{MoS}_{2}$ particles and the cross-sectional SEM image (d) of the $\mathrm{P}$ (NIPAM-co-AAc)/ $\mathrm{MoS}_{2}$ composite hydrogel.

mode $\left(A_{1 g}\right)$ and the in-plane vibration mode $\left(E_{2 g}^{1}\right)$, respectively. ${ }^{55}$ In the Raman spectrum of the $\mathrm{P}$ (NIPAM-coAAc) hydrogel without $\mathrm{MoS}_{2}$, a wide band was found at 1000$2000 \mathrm{~cm}^{-1}$, indicating the amorphous dried hydrogel, and no $\mathrm{MoS}_{2}$ characteristic peak was found. When the $\mathrm{MoS}_{2}$ loading content is low, there are rather weak peaks belonging to $\mathrm{MoS}_{2}$ in the Raman spectrum of $\mathrm{P}(\mathrm{NIPAM}-\mathrm{co}-\mathrm{AAc}) / \mathrm{MoS}_{2}$. When the $\mathrm{MoS}_{2}$ content reaches more than $10 \mathrm{mg}$, the characteristic peak of $\mathrm{MoS}_{2}$ appears, indicating that $\mathrm{MoS}_{2}$ has been successfully incorporated into the P(NIPAM-co-AAc) hydrogel. As seen in Figure 2b, compared to NG-4, NG-5 with a higher $\mathrm{MoS}_{2}$ content should have an increased intensity of the characteristic Raman absorbance bands. However, the intensity of the characteristic $\mathrm{MoS}_{2}$ peaks at about 403 and $374 \mathrm{~cm}^{-1}$ in NG-5 was slightly lower than that in NG-4. It is most likely that at a very high concentration (2.5\%) of $\mathrm{MoS}_{2}$ dispersion during the preparation of NG-5, the inorganic $\mathrm{MoS}_{2}$ particles are becoming unstable and prone to form aggregates, resulting in an uneven composition of the $\mathrm{P}$ (NIPAM-co-AAc)/ $\mathrm{MoS}_{2}$ composite hydrogels. At a lower $\mathrm{MoS}_{2}$ content, because the hydrogel encapsulates and shields $\mathrm{MoS}_{2}$, the characteristic peaks of $\mathrm{MoS}_{2}$ are not obvious in the spectrum.

Thermogravimetric analysis (TGA) should be used for detecting the $\mathrm{MoS}_{2}$ content in the $\mathrm{P}(\mathrm{NIPAM}-\mathrm{co}-\mathrm{AAc}) / \mathrm{MoS}_{2}$ composite hydrogels. Figure $\mathrm{S} 1 \mathrm{a}$ shows the TGA curves of $\mathrm{P}$ (NIPAM-co-AAc) and $\mathrm{P}(\mathrm{NIPAM}-\mathrm{co}-\mathrm{AAc}) / \mathrm{MoS}_{2}$ composite hydrogels. Figure $\mathrm{S} 1 \mathrm{~b}$ shows an enlarged part of the indicated area with a green frame in Figure S1a. From Figure S1, it can be seen that the char residual mass ratio of the pure $\mathrm{P}$ (NIPAM-co-AAc) hydrogel NG-1 is about $5.54 \%$. The char residual mass ratio of $\mathrm{P}(\mathrm{NIPAM}-\mathrm{co}-\mathrm{AAc}) / \mathrm{MoS}_{2}$ composite hydrogels including NG-3, NG-4, and NG-5 are 5.97, 6.61, and $8.11 \%$, respectively. The $\mathrm{MoS}_{2}$ contents of NG-3, NG-4, and NG-5 were calculated to be $0.43,1.07$, and $2.57 \%$, respectively. 

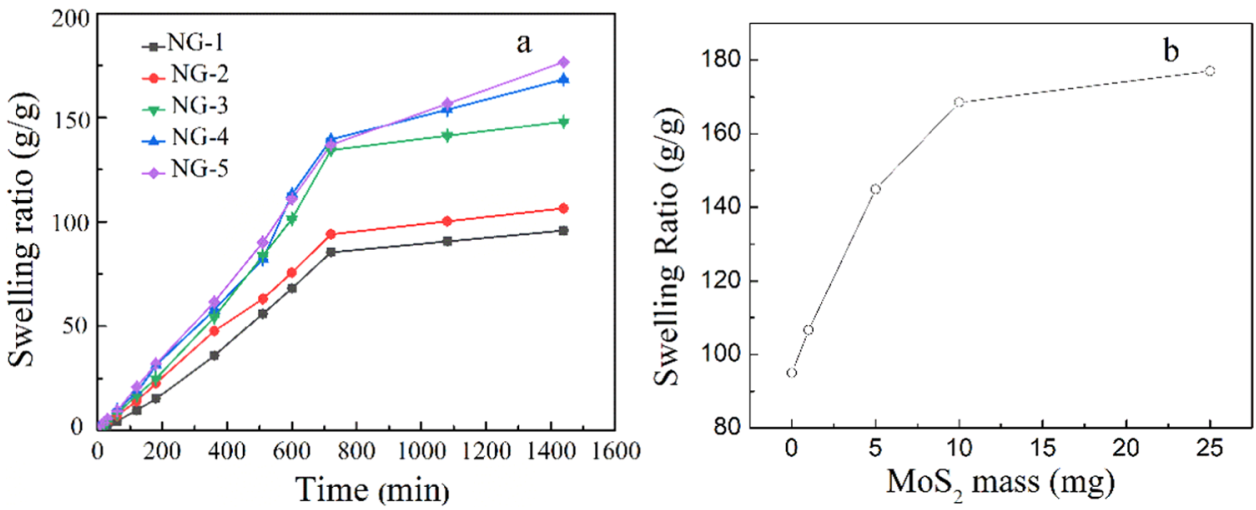

Figure 4. Swelling ratio of the $\mathrm{P}(\mathrm{NIPAM}-\mathrm{co}-\mathrm{AAc})$ hydrogel and the $\mathrm{P}(\mathrm{NIPAM}-\mathrm{co}-\mathrm{AAc}) / \mathrm{MoS}_{2}$ composite hydrogel as a function of time (a), and the equilibrium swelling ratio of hydrogels as a function of the $\mathrm{MoS}_{2}$ loading content (b).
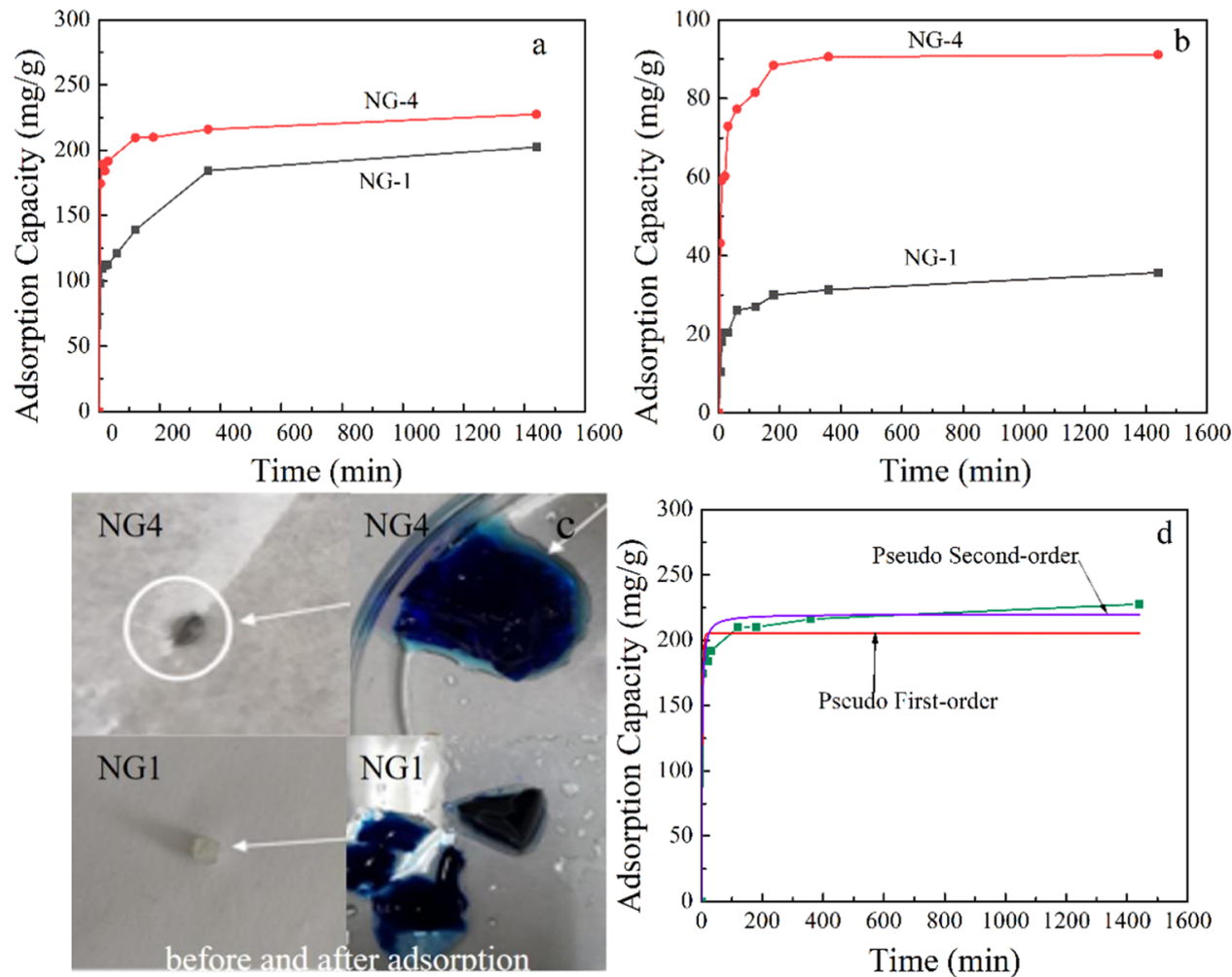

Figure 5. Dye adsorption capacity of $\mathrm{P}(\mathrm{NIPAM}-\mathrm{co}-\mathrm{AAc}) / \mathrm{MoS}_{2}$ and $\mathrm{P}(\mathrm{NIPAM}-\mathrm{co}-\mathrm{AAc})$ hydrogels as a function of time at room temperature (a) and $40{ }^{\circ} \mathrm{C}(\mathrm{b})$; (c) appearance of the hydrogels before and after adsorption; and (d) adsorption curve of MB by the composite hydrogel and the adsorption kinetic models at room temperature.

The calculated values are very consistent with the theoretical values.

Figure $3 \mathrm{a}$ shows the scanning electron microscope (SEM) image of $\mathrm{MoS}_{2}$ particles. It can be seen from Figure 3a that $\mathrm{MoS}_{2}$ exists in the form of flakes. Through statistical average, the average size of the flake diameter of $\mathrm{MoS}_{2}$ is about $3.2 \mu \mathrm{m}$. Using transmission electron microscope (TEM) to analyze the single irregularly shaped particle of $\mathrm{MoS}_{2}$ (see Figure 3b), the size of the $\mathrm{MoS}_{2}$ flake is about $3.4 \mu \mathrm{m}$. Figure $3 \mathrm{c}$ shows the $\zeta$ potential distribution of $\mathrm{MoS}_{2}$ particles. The $\zeta$-potential of particles is considered to be an important parameter for characterizing the stability of the colloidal dispersions and gives information on the effective surface charge. As shown in Figure $3 c$, it can be seen that the $\zeta$-potential of $\mathrm{MoS}_{2}$ particles is about $-27.5 \mathrm{mV}$, indicating that the dispersion is relatively stable and the electrostatic force is large. Since $\mathrm{MoS}_{2}$ is negatively charged, it is beneficial to adsorb oppositely charged dye molecules through an electrostatic force. The P(NIPAMco-AAc) hydrogel system was introduced with $\mathrm{MoS}_{2}$, and the resulting composite hydrogel (NG-4) was freeze-dried and fractured with liquid nitrogen. The cross-sectional SEM image is shown in Figure 3d. It can be seen from Figure 3d that the cross-sectional morphology of the composite hydrogel is a three-dimensional porous network structure, and the pore walls are relatively thin. The pore size is about $100 \mu \mathrm{m}$. The porous structure has different morphologies, indicating that the area is filled with water.

Figure 4 shows the swelling ratio of the $\mathrm{P}(\mathrm{NIPAM}-\mathrm{co}-\mathrm{AAc})$ hydrogel (NG-1) and the $\mathrm{P}(\mathrm{NIPAM}-\mathrm{co}-\mathrm{AAc}) / \mathrm{MoS}_{2}$ composite hydrogel (NG-4) with time, and the relationship between 
Table 2. Kinetic Parameters for the Adsorption of MB in P(NIPAM-co-AAc) and P(NIPAM-co-AAc)/MoS 2 Hydrogels at Room Temperature

\begin{tabular}{|c|c|c|c|c|c|c|}
\hline \multirow[b]{2}{*}{ sample } & \multicolumn{3}{|c|}{ pseudo-first-order constants } & \multicolumn{3}{|c|}{ pseudo-second-order constants } \\
\hline & $q_{\mathrm{e}}(\mathrm{mg} / \mathrm{g})$ & $K_{1}\left(\min ^{-1}\right)$ & $R^{2}$ & $q_{\mathrm{e}}(\mathrm{mg} / \mathrm{g})$ & $K_{2}(\mathrm{~g} / \mathrm{mg} \times \mathrm{min})$ & $R^{2}$ \\
\hline $\mathrm{P}(\mathrm{NIPAM}-\mathrm{co}-\mathrm{AAc}) / \mathrm{MoS}_{2}$ & 205.5 & 0.354 & 0.963 & 212.5 & 3.503 & 0.982 \\
\hline
\end{tabular}

the equilibrium swelling ratio and the amount of $\mathrm{MoS}_{2}$ added. As shown in Figure $4 \mathrm{a}$, the swelling ratio of the P(NIPAM-coAAc) hydrogel without $\mathrm{MoS}_{2}$ is first increased with time from 0 to $12 \mathrm{~h}$. It then changes slowly after $12 \mathrm{~h}$, and the final swelling ratio reaches about $95 \mathrm{~g} / \mathrm{g}$. The $\mathrm{P}(\mathrm{NIPAM}-\mathrm{co}-\mathrm{AAc}) /$ $\mathrm{MoS}_{2}$ composite hydrogel obtained after the addition of $\mathrm{MoS}_{2}$ shows a similar change trend. The final equilibrium swelling ratio is higher than that of the pure $\mathrm{P}$ (NIPAM-co-AAc) hydrogel. Figure $4 \mathrm{~b}$ shows the relationship curve between the equilibrium swelling ratio of $\mathrm{P}(\mathrm{NIPAM}-\mathrm{co}-\mathrm{AAc}) / \mathrm{MoS}_{2}$ composite hydrogels and the amount of the added $\mathrm{MoS}_{2}$. It can be seen that the equilibrium swelling ratio began to increase sharply with the increase of the amount of $\mathrm{MoS}_{2}$ and tended to be stable when the amount of addition was 10 and $25 \mathrm{mg}$. When $25 \mathrm{mg}$ is added, the equilibrium swelling ratio of the $\mathrm{P}$ (NIPAM-co-AAc) $/ \mathrm{MoS}_{2}$ composite hydrogel can reach 176.5 $\mathrm{g} / \mathrm{g}$. This is mainly because $\mathrm{MoS}_{2}$ itself has oxygen-containing groups on the surface and is negatively charged. As the amount of the added $\mathrm{MoS}_{2}$ increases, the hydrophilicity of the composite hydrogel improves, leading to the expansion of the networks. At the same time, because $\mathrm{MoS}_{2}$ itself is negatively charged, the increase of $\mathrm{MoS}_{2}$ caused the electrostatic repulsion of the same charged counterparts in the network structure, resulting in an increase in the volume and swelling ratio. The excellent swelling performance indicates that the composite hydrogel may have a high dye adsorption capacity.

Figure 5 shows the relationship between the amount of dye adsorption of $\mathrm{P}(\mathrm{NIPAM}-\mathrm{co}-\mathrm{AAc}) / \mathrm{MoS}_{2}$ and $\mathrm{P}(\mathrm{NIPAM}-\mathrm{co}-$ $\mathrm{AAc}$ ) hydrogels as a function of time at room temperature and $40{ }^{\circ} \mathrm{C}$, as well as the appearance of the hydrogel before and after adsorption, and the adsorption kinetic models of MB by the hydrogel. Note that the initial concentration of $\mathrm{MB}$ for the adsorption experiment is $64 \mathrm{mg} / \mathrm{L}$. It can be seen from Figure 5 a that with the extension of time, the adsorption capacity of both $\mathrm{P}$ (NIPAM-co-AAc) $/ \mathrm{MoS}_{2}$ and P(NIPAM-co-AAc) hydrogels for $\mathrm{MB}$ both gradually increases. After $6 \mathrm{~h}$, the adsorption kinetic process reaches equilibrium and the adsorption kinetic curve attains a plateau. At equilibrium, the adsorption capacity of P(NIPAM-co-AAc)/ $\mathrm{MoS}_{2}$ and P(NIPAM-co-AAc) hydrogels is 227 and $202 \mathrm{mg} / \mathrm{g}$, respectively. The P(NIPAM-co-AAc) hydrogel has a porous network structure, a large area, and numerous channels, which is conducive to the diffusion and adsorption of the positively charged dye molecules. Moreover, the cross-linked network structure has ionizable carboxyl groups $-\mathrm{COO}^{-}$, which is negatively charged and can absorb the positively charged $\mathrm{MB}$ dye molecules through electrostatic attraction. In addition, due to the presence of the $-\mathrm{COOH}$ group on the network structure, the cationic organic dye molecule $\mathrm{MB}$ can also interact with the hydrogel through hydrogen bonds. ${ }^{56}$ Compared with the $\mathrm{P}(\mathrm{NIPAM}-\mathrm{co}-\mathrm{AAc})$ hydrogel, the $\mathrm{P}$ (NIPAM-co-AAc)/MoS 2 composite hydrogel has $\mathrm{MoS}_{2}$ particles, which have a negative charge and can also adsorb the cationic dye MB through electrostatic interactions, leading to an increased adsorption capacity.
Figure $5 \mathrm{~b}$ shows the relationship between the adsorption capacity of $\mathrm{P}$ (NIPAM-co-AAc) $/ \mathrm{MoS}_{2}$ and $\mathrm{P}$ (NIPAM-co-AAc) hydrogels as a function of time at $40{ }^{\circ} \mathrm{C}$. The initial concentration of the $\mathrm{MB}$ solution is $64 \mathrm{mg} / \mathrm{L}$. It can be seen from Figure $5 b$ that with the increase of time, the adsorption capacity of $\mathrm{P}$ (NIPAM-co-AAc) $/ \mathrm{MoS}_{2}$ and $\mathrm{P}$ (NIPAM-co-AAc) hydrogels to $\mathrm{MB}$ is gradually increased and begins to reach adsorption equilibrium at about $6 \mathrm{~h}$. The adsorption capacity of P(NIPAM-co-AAc)/ $\mathrm{MoS}_{2}$ and P(NIPAM-co-AAc) hydrogels at equilibrium is 91 and $35 \mathrm{mg} / \mathrm{g}$, respectively. By comparing the results from Figure $5 \mathrm{a}, \mathrm{b}$, the adsorption temperature greatly influences the adsorption capacity of both hydrogels. With the increase of the adsorption temperature, when the dye adsorption is performed above the phase transition temperature near $32{ }^{\circ} \mathrm{C}$, the adsorption capacity of $\mathrm{P}(\mathrm{NIPAM}-\mathrm{co}-\mathrm{AAc}) / \mathrm{MoS}_{2}$ and $\mathrm{P}(\mathrm{NIPAM}-\mathrm{co}-\mathrm{AAc})$ hydrogels at equilibrium was both also decreased. This shows that the hydrogel swells in the solution at room temperature, the molecular chain stretches, the three-dimensional porous crosslinked network structure, and numerous channels are beneficial to the diffusion and adsorption of dye molecules. Above the phase transition temperature of $32{ }^{\circ} \mathrm{C}$, the macromolecular chain collapses and water is discharged. The three-dimensional cross-linked network structure shrinks, which is not conducive to the diffusion and adsorption of dye molecules, resulting in lower dye adsorption quantity.

Figure 5c shows the appearance of P(NIPAM-co-AAc)/ $\mathrm{MoS}_{2}$ and P(NIPAM-co-AAc) hydrogels before adsorption. Both freeze-dried samples with the same mass of $10 \mathrm{mg}$ are much smaller. The freeze-dried hydrogel containing $\mathrm{MoS}_{2}$ is black granules, while the one without $\mathrm{MoS}_{2}$ is white. After MB dye molecules are adsorbed, the hydrogel volume is much larger than the original one, and the color is blue, indicating that $\mathrm{MB}$ dye molecules are absorbed on the surface and bound to the hydrogel. Considering that the P(NIPAM-co-AAc)/ $\mathrm{MoS}_{2}$ composite hydrogel has a high dye adsorption capacity, Figure $5 \mathrm{~d}$ shows the adsorption kinetics and simulation curves of $\mathrm{MB}$ adsorption on the $\mathrm{P}(\mathrm{NIPAM}-\mathrm{co}-\mathrm{AAc}) / \mathrm{MoS}_{2}$ composite hydrogels at room temperature. The experimental data are fitted with two kinetic models, pseudo-first-order and pseudosecond-order models (see eqs 1 and 2).

$$
\begin{aligned}
& \frac{\mathrm{d}_{q_{t}}}{\mathrm{~d}_{t}}=k_{1}\left(q_{\mathrm{e}}-q_{t}\right) \\
& \frac{\mathrm{d}_{q_{t}}}{\mathrm{~d}_{t}}=k_{2}\left(q_{\mathrm{e}}-q_{t}\right)^{2}
\end{aligned}
$$

where $q_{\mathrm{e}}$ and $q_{t}(\mathrm{mg} / \mathrm{g})$ represent the equilibrium adsorption capacity and the adsorption capacity at contacting time $t$, and $k_{1}$ and $k_{2}$ are pseudo-first-order constant and pseudo-secondorder constant. Table 2 shows the kinetic parameters for the adsorption of $\mathrm{MB}$ in $\mathrm{P}$ (NIPAM-co-AAc) and P(NIPAM-coAAc) $/ \mathrm{MoS}_{2}$ hydrogels at room temperature. From Figure $5 \mathrm{~d}$ and Table 2, it can be seen that at room temperature, the correlation coefficient value $\left(R^{2}\right)$ of the pseudo-second-order 



Figure 6. Adsorption isotherms of $\mathrm{P}(\mathrm{NIPAM}-\mathrm{co}-\mathrm{AAc}) / \mathrm{MoS}_{2}$ and $\mathrm{P}(\mathrm{NIPAM}-\mathrm{co}-\mathrm{AAc})$ hydrogels for $\mathrm{MB}$ at room temperature (a) and $40{ }^{\circ} \mathrm{C}(\mathrm{b})$, and the plotting curves of Langmuir and Freundlich isotherm adsorption models (c) and the ARIAN model (d) for the MB adsorption of $\mathrm{P}(\mathrm{NIPAM}-\mathrm{co}-\mathrm{AAc}) / \mathrm{MoS}_{2}$ at room temperature.

model reaches 0.982 , which is higher than that for the pseudofirst-order model. This indicates that the adsorption of $\mathrm{MB}$ dye molecules onto $\mathrm{P}$ (NIPAM-co-AAc)/ $\mathrm{MoS}_{2}$ composite hydrogels follows the pseudo-second-order model well.

As indicated in the literature, ${ }^{57}$ the kinetics of adsorption study in the regions with constant adsorption acceleration (abbreviated as KASRA) model was also used to calculate the kinetics of the adsorption process. According to the KASRA model, the adsorption kinetics curve is composed of two regions ( 1 and 2). Regions 1 and 2 like regions I and II in adsorption isotherms are belonging to the most active and rest of sites, respectively. Several first data and then remaining data were fitted in a quadratic KASRA equation (see eqs $S 1-S 3$ in the Supporting Information). The adsorption kinetic experiment was performed at a MB initial concentration of $64 \mathrm{mg} / \mathrm{L}$. The obtained data were analyzed by the KASRA model, as shown in Figure S1 and Table S1. As shown in Figure S1 and Table S1, the kinetic curves are composed of two regions (1 and 2). Regions 1 and 2 like regions I and II in adsorption isotherms pay to the most active and rest of sites, respectively. We fit several first data and then the remaining data in a quadratic equation. In region 1 , the coefficients including $A, B$, and $R^{2}$ of the KASRA equation are calculated to be -0.613 , 24.12 , and 0.706 , respectively. In region $2, A, B, C$, and $R^{2}$ are estimated to be $-4.28 \times 10^{-5}, 0.085,194.17$, and 0.89 , respectively. As indicated in the results above, the experimental data were fitted with two kinetic models, pseudo-first-order and pseudo-second-order models (see eqs 1 and 2). It can be seen that at room temperature, the correlation coefficient values $\left(R^{2}\right)$ of pseudo-second-order and pseudo-first-order models reach 0.982 and 0.963 , which are both higher than the two values of 0.706 and 0.890 at $40{ }^{\circ} \mathrm{C}$. This indicates that the adsorption of $\mathrm{MB}$ dye molecules onto $\mathrm{P}(\mathrm{NIPAM}-\mathrm{co}-\mathrm{AAc}) /$ $\mathrm{MoS}_{2}$ composite hydrogels follows the pseudo-second-order model well. Also, in most of the literature studies ${ }^{28,58-63}$ (see Table 5), the adsorption kinetics of the hydrogels for MB is well described with the pseudo-second-order or pseudo-firstorder models. To compare our results with the data reported in the literature, we would keep the results and discussion on the kinetics study using pseudo-second-order and pseudo-firstorder models.

Figure $6 \mathrm{a}, \mathrm{b}$ shows the adsorption isotherms of $\mathrm{P}$ (NIPAM-coAAc) $/ \mathrm{MoS}_{2}$ and $\mathrm{P}$ (NIPAM-co-AAc) hydrogels for MB at room temperature and $40{ }^{\circ} \mathrm{C}$. Figure $6 \mathrm{c}$ indicates the plotting curves of Langmuir and Freundlich isotherm adsorption models. It can be seen from Figure $6 a$ that with the increase of the equilibrium concentration, the adsorption capacity of $\mathrm{P}$ (NIPAM-co-AAc) $/ \mathrm{MoS}_{2}$ and P(NIPAM-co-AAc) hydrogels to $\mathrm{MB}$ dye increases, and the $\mathrm{P}(\mathrm{NIPAM}-\mathrm{co}-\mathrm{AAc}) / \mathrm{MoS}_{2}$ composite hydrogel has better adsorption performance than the $\mathrm{P}$ (NIPAM-co-AAc) hydrogel. The P(NIPAM-co-AAc) hydrogel has an adsorption effect, which is due to the AAc component in the hydrogel. Polyacrylic acid is a polyelectrolyte that can ionize protons in the aqueous solution to render the polymer negatively charged, while $\mathrm{MB}$ is the positively charged organic dye molecule. Therefore, the two can be combined through electrostatic interactions so that the P(NIPAM-coAAc) hydrogel has an adsorption effect. The addition of $\mathrm{MoS}_{2}$ makes the adsorption performance of hydrogel better because $\mathrm{MoS}_{2}$ has a hexagonal sheet structure similar to graphene, has a 
Table 3. Langmuir and Freundlich Isotherm Parameters for the Adsorption of MB onto P(NIPAM-co-AAc)/MoS 2 Hydrogels at Room Temperature

\begin{tabular}{|c|c|c|c|c|c|c|}
\hline \multirow[b]{2}{*}{ sample } & \multicolumn{3}{|c|}{ Langmuir isotherm parameters } & \multicolumn{3}{|c|}{ Freundlich isotherm parameters } \\
\hline & $q_{\mathrm{m}}(\mathrm{mg} / \mathrm{g})$ & $K_{\mathrm{L}}(\mathrm{L} / \mathrm{mg})$ & $R^{2}$ & $K_{\mathrm{F}}(\mathrm{mg} / \mathrm{g})$ & $1 / n$ & $R^{2}$ \\
\hline $\mathrm{P}(\mathrm{NIPAM}-\mathrm{co}-\mathrm{AAc}) / \mathrm{MoS}_{2}$ & 1258 & 0.0051 & 0.994 & 34.7 & 0.523 & 0.950 \\
\hline
\end{tabular}

large specific surface area, and is negatively charged, which can adsorb a large amount of $\mathrm{MB}$ through the electrostatic attraction and van der Waals forces. This shows that the addition of $\mathrm{MoS}_{2}$ can improve the adsorption performance of the pure $\mathrm{P}$ (NIPAM-co-AAc) hydrogel. The adsorption capacity of the $\mathrm{P}(\mathrm{NIPAM}-\mathrm{co}-\mathrm{AAc}) / \mathrm{MoS}_{2}$ composite hydrogel can reach $916 \mathrm{mg} / \mathrm{g}$ when the $\mathrm{MB}$ initial concentration is $640 \mathrm{mg} / \mathrm{L}$.

It can be seen from Figure $6 \mathrm{~b}$ that at $40{ }^{\circ} \mathrm{C}$, the adsorption capacity of $\mathrm{P}$ (NIPAM-co-AAc)/ $\mathrm{MoS}_{2}$ and $\mathrm{P}$ (NIPAM-co-AAc) hydrogels show a trend similar to that at room temperature with the increase of the $\mathrm{MB}$ concentration. Compared to room temperature, the increased adsorption temperature of $40{ }^{\circ} \mathrm{C}$ leads to the decreased adsorption capacity of P(NIPAM-co$\mathrm{AAc}) / \mathrm{MoS}_{2}$ and $\mathrm{P}$ (NIPAM-co-AAc) hydrogels at different concentrations. This is because the PNIPAM hydrogel is temperature-sensitive and has a characteristic phase transition temperature. At the adsorption temperature of $40{ }^{\circ} \mathrm{C}$ above the phase transition temperature $\left(32^{\circ} \mathrm{C}\right)$, the volume of hydrogels shrinks sharply. At room temperature, water molecules interact strongly with amide groups through hydrogen bonds, resulting in the PNIPAM hydrogels having a good affinity with water molecules. When the temperature is higher than the phase transition temperature, the hydrogen bonds between water molecules and amide groups are destroyed, and the hydrophilic force is weakened. The polymer chains are collapsed, and the volume of hydrogels shrinks significantly. At the same time, the chance of $\mathrm{MB}$ entering the hydrogel is reduced, and the amount of $\mathrm{MB}$ binding with the hydrogel is decreased. Therefore, as the temperature increases, the adsorption capacity of $\mathrm{P}$ (NIPAM-co-AAc)/ $\mathrm{MoS}_{2}$ and $\mathrm{P}$ (NIPAM-co-AAc) hydrogels are both reduced. When the initial concentration of $\mathrm{MB}$ is $640 \mathrm{mg} / \mathrm{L}$, the adsorption capacity of the P(NIPAM-co$\mathrm{AAc}) / \mathrm{MoS}_{2}$ composite hydrogel decreases from 916 to 620 $\mathrm{mg} / \mathrm{g}$, and the adsorption capacity of the P(NIPAM-co-AAc) hydrogel is reduced from 598 to $402 \mathrm{mg} / \mathrm{g}$.

Figure $6 c$ shows the plotting curves of Langmuir and Freundlich isotherm adsorption models for the MB adsorption of $\mathrm{P}$ (NIPAM-co-AAc)/ $\mathrm{MoS}_{2}$ at room temperature. As shown in Figure $6 \mathrm{c}$, as the equilibrium concentration of $\mathrm{MB}$ increases, the equilibrium adsorption capacity of the P(NIPAM-co-AAc)/ $\mathrm{MoS}_{2}$ composite hydrogel for $\mathrm{MB}$ increases. Langmuir (eq 3) and Freundlich (eq 4) isotherm models were used to evaluate the relationship between the equilibrium adsorption capacity of the P(NIPAM-co-AAc)/ $\mathrm{MoS}_{2}$ composite hydrogel for MB and the equilibrium $\mathrm{MB}$ concentration.

$$
\begin{aligned}
& q_{\mathrm{e}}=\frac{q_{\mathrm{m}} K_{\mathrm{L}} C_{\mathrm{e}}}{1+K_{\mathrm{L}} C_{\mathrm{e}}} \\
& q_{\mathrm{e}}=K_{\mathrm{F}} C_{\mathrm{e}}^{1 / n}
\end{aligned}
$$

where $q_{\mathrm{m}}(\mathrm{mg} / \mathrm{g}), 1 / n, q_{\mathrm{e}}(\mathrm{mg} / \mathrm{g}), C_{\mathrm{e}}(\mathrm{mg} / \mathrm{L}), K_{\mathrm{L}}(\mathrm{L} / \mathrm{mg})$, and $K_{\mathrm{F}}(\mathrm{mg} / \mathrm{g})$ represent maximum adsorption capacity, adsorption intensity, adsorption capacity, the equilibrium concentration of MB dyes, the Langmuir constant, and the Freundlich constant, respectively. Table 3 shows Langmuir and Freundlich isotherm parameters for the adsorption of $\mathrm{MB}$ onto $\mathrm{P}$ (NIPAM-co-AAc) $/ \mathrm{MoS}_{2}$ hydrogels at room temperature. From Figure $6 \mathrm{c}$ and Table 3 , it can be seen that the adsorption isotherm of the $\mathrm{P}$ (NIPAM-co-AAc) $/ \mathrm{MoS}_{2}$ composite hydrogel for $\mathrm{MB}$ at room temperature is more consistent with the Langmuir adsorption isotherm model, and $R^{2}=0.994$. According to the Langmuir isotherm adsorption model simulation, the maximum adsorption capacity of the P(NIPAM-co-AAc) $/ \mathrm{MoS}_{2}$ composite hydrogel can reach 1258 $\mathrm{mg} / \mathrm{g}$.

As reported in the literature, ${ }^{57}$ the "adsorption isotherm regional analysis model” (abbreviated as ARIAN model) should be used to analyze the adsorption isotherm of hydrogels. Figure $6 \mathrm{~d}$ shows the ARIAN model for the $\mathrm{MB}$ adsorption of $\mathrm{P}$ (NIPAM-co-AAc) $/ \mathrm{MoS}_{2}$ at room temperature. First, several data (region I) were fit in the Henry equation (eq 5 ), and the rest of them (region II) were fit in the Temkin equation (eq 6). Because the adsorbent surface in our work is nonideal, it is not appropriate to use the Langmuir isotherm to fit. The Temkin equation is a suitable equation for the nonideal surface. The adsorption equilibrium constants can be obtained using them. Table 4 shows the ARIAN model isotherm

Table 4. ARIAN Model Isotherm Parameters for the Adsorption of MB onto P(NIPAM-co-AAc)/ $\mathrm{MoS}_{2}$ Hydrogels at Room Temperature

\begin{tabular}{ccccccc} 
& \multicolumn{2}{c}{ Henry's Law } & & \multicolumn{3}{c}{ Temkin } \\
\cline { 2 - 3 } \cline { 5 - 6 } sample & $K$ & $R^{2}$ & & $C_{1}$ & $C_{2}$ & $R^{2}$ \\
$\mathrm{P}(\mathrm{NIPAM}-\mathrm{co}-\mathrm{Ac}) / \mathrm{MoS}_{2}$ & 4.927 & 0.983 & & 247.5 & 0.068 & 0.955 \\
\hline
\end{tabular}

parameters for the adsorption of MB onto P(NIPAM-co-AAc)/ $\mathrm{MoS}_{2}$ hydrogels at room temperature. As shown in Table 4, the parameters of $K$ and $R^{2}$ for Henry's Law are 4.927 and 0.983, respectively. In addition, $C_{1}, C_{2}$, and $R^{2}$ for the Temkin equation are $247.5,0.068$, and 0.955 , respectively. The maximum experimental $q_{\mathrm{e}}$ is equal to the experimental $q_{\mathrm{e}}$ of $916 \mathrm{mg} / \mathrm{g}$ (initial MB concentration of $640 \mathrm{mg} / \mathrm{L}$ ) after 650 min but not values calculated by the Langmuir model. Actually, Langmuir and Freundlich isotherm parameters for the adsorption of $\mathrm{MB}$ onto $\mathrm{P}(\mathrm{NIPAM}-\mathrm{co}-\mathrm{AAc}) / \mathrm{MoS} 2$ hydrogels at room temperature were calculated and their $R^{2}$ values were 0.994 and 0.950 , respectively, which is much higher than that of 0.955 obtained by the ARIAN model. It can be seen that the adsorption isotherm of the $\mathrm{P}$ (NIPAM-co-AAc) $/ \mathrm{MoS}_{2}$ composite hydrogel for $\mathrm{MB}$ at room temperature is more consistent with the Langmuir adsorption isotherm model. According to the Langmuir isotherm adsorption model simulation, the maximum adsorption capacity of the P(NIPAM-co-AAc)/ $\mathrm{MoS}_{2}$ composite hydrogel can reach $1258 \mathrm{mg} / \mathrm{g}$. Actually, in most literature studies ${ }^{58,60,62-64}$ (see Table 5), the adsorption isotherm was well fitted with the Langmuir model. To better compare our results with the reported data in the literature, we would keep the results and discussion on the modeling of Langmuir and Freundlich isotherm. 
Table 5. Adsorption Isotherm Constants of Some Adsorbents for MB

\begin{tabular}{|c|c|c|}
\hline adsorbents & $\underset{(\mathrm{mg} / \mathrm{g})}{q_{\mathrm{m}}}$ & references \\
\hline $\begin{array}{l}\beta \text {-cyclodextrin/poly (acrylic acid) grafted onto } \\
\text { graphene oxide }(\beta \text {-CD/PAA/GO) hydrogels }\end{array}$ & 248 & 64 \\
\hline polydopamine microspheres & 90.7 & 58 \\
\hline $\begin{array}{l}\text { the modified banana pseudo-stem cellulose } \\
\text { backbone with sodium acrylate (NaAc) and } \\
\text { acrylamide (AM) onto } \\
\text { (BPCMC-g-poly(NaAc-co-AM)) }\end{array}$ & 333 & 59 \\
\hline mesoporous carbon material from fishery waste & 184.4 & 60 \\
\hline cellulose nanocrystal-alginate hydrogel beads & 255.5 & 65 \\
\hline $\begin{array}{l}\text { core@double-shell-structured magnetic halloysite } \\
\text { nanotube }\end{array}$ & 714.29 & 61 \\
\hline $\begin{array}{l}\text { polyacrylamide/chitosan } / \mathrm{Fe}_{3} \mathrm{O}_{4} \text { composite } \\
\text { hydrogels }\end{array}$ & 1603 & 28 \\
\hline poly(acrylic acid)/laponite hydrogel & 3846 & 62 \\
\hline villilike poly(acrylic acid)-based hydrogel & 2249 & 63 \\
\hline $\mathrm{P}(\mathrm{NIPAM}-\mathrm{co}-\mathrm{AAc}) / \mathrm{MoS}_{2}$ hydrogels & 1258 & this work \\
\hline
\end{tabular}

where $K$ is the binding constant of the adsorbate on the surface and adsorption increases linearly with the concentration.

$$
q_{\mathrm{e}}=C_{1} \ln \left(C_{2} C_{\mathrm{e}}\right)
$$

where $C_{1}$ is a constant and $C_{2}$ is the adsorption equilibrium constant.

At room temperature and $40{ }^{\circ} \mathrm{C}$, there is one kind of adsorption site on the surface of the hydrogel. Due to changes in the structure of the hydrogel, the most active sites located on the wider channels interact with $\mathrm{MB}$ first. After sufficiently increasing the concentration of $\mathrm{MB}$ in the adsorbent, they interact with adsorption sites in a narrower space. $\mathrm{MoS}_{2}$ stabilizes the hydrogel structure and makes its channels or internal space wider. $\mathrm{MoS}_{2}$ acts in the adsorbent like a scaffolding for hydrogel. Thus, in spite of the fact that the amount of $\mathrm{MoS}_{2}$ in NG-4 is more than that in NG-1, more numbers of adsorption sites of NG-4 are exposed to $\mathrm{MB}$ molecules.

Nowadays, a large number of adsorbents have been developed to treat $\mathrm{MB}$ dyes in sewage. Table 5 lists the maximum adsorption capacity of some adsorbents. In Table 5, most of the work reported show the adsorption capacity from 90 to $715 \mathrm{mg} / \mathrm{g}$ for $\mathrm{MB}$. Some representative work including polyacrylamide/chitosan $/ \mathrm{Fe}_{3} \mathrm{O}_{4}$ composite hydrogels, poly(acrylic acid)/laponite hydrogel, and villilike poly(acrylic acid)-based hydrogel has also been listed in Table 5. It can be seen that the maximum adsorption capacity of 1603, 3846, and $2249 \mathrm{mg} / \mathrm{g}$ for $\mathrm{MB}$ is reported, respectively. Compared with the adsorbents reported in the literature, the P(NIPAMco-AAc) $/ \mathrm{MoS}_{2}$ composite hydrogel in this work still has an advantage and shows a high adsorption capacity of $1258 \mathrm{mg} / \mathrm{g}$ for MB.

\section{CONCLUSIONS}

Through the analysis of FT-IR, Raman, and SEM, it is proved that the $\mathrm{P}$ (NIPAM-co-AAc)/ $\mathrm{MoS}_{2}$ composite hydrogel was successfully prepared by simple free radical polymerization. SEM images of the cross section of the P(NIPAM-co-AAc)/ $\mathrm{MoS}_{2}$ composite hydrogel showed that the composite hydrogel had a porous network structure. Hydrogels are hydrophilic and can absorb large amounts of water. By studying the swelling properties of $\mathrm{P}$ (NIPAM-co-AAc) and $\mathrm{P}$ (NIPAM-co-AAc)/ $\mathrm{MoS}_{2}$ hydrogels, the results show that $\mathrm{MoS}_{2}$ can increase the swelling ratio of $\mathrm{P}$ (NIPAM-co-AAc) to a certain extent due to its negatively charged surface. The $\mathrm{P}(\mathrm{NIPAM}-\mathrm{co}-\mathrm{AAc}) / \mathrm{MoS}_{2}$ composite hydrogel with $25 \mathrm{mg}$ of $\mathrm{MoS}_{2}$ can have a swelling ratio of nearly 176.50. The addition of $\mathrm{MoS}_{2}$ can effectively improve the adsorption performance of the P(NIPAM-co-AAc) hydrogel. When the initial concentration of $\mathrm{MB}$ is $640 \mathrm{mg} / \mathrm{L}$, the maximum adsorption capacity calculated by the Langmuir isotherm adsorption model can reach about $1258 \mathrm{mg} / \mathrm{g}$. By studying the adsorption performance of the P(NIPAM-coAAc) $/ \mathrm{MoS}_{2}$ composite hydrogel at different temperatures, it is observed that as the temperature increases to $40{ }^{\circ} \mathrm{C}$, the adsorption performance of the $\mathrm{P}(\mathrm{NIPAM}-\mathrm{co}-\mathrm{AAc}) / \mathrm{MoS}_{2}$ composite hydrogel is weakened. The adsorption isotherm of the $\mathrm{P}$ (NIPAM-co-AAc)/ $\mathrm{MoS}_{2}$ composite hydrogel for $\mathrm{MB}$ at room temperature conforms to the Langmuir isotherm adsorption model. The adsorption process of $\mathrm{MB}$ by the $\mathrm{P}$ (NIPAM-co-AAc) $/ \mathrm{MoS}_{2}$ composite hydrogel at room temperature fit well the pseudo-second-order kinetics model. This research provides a facile method for developing dye adsorption materials with high adsorption capacity.

\section{EXPERIMENTAL SECTION}

Chemicals and Materials. N-Isopropylacrylamide (NIPAM, 99\%), acrylic acid (AAc, 98\%), and methylene blue (MB) were purchased from Sinopharm Chemical Reagent Co., Ltd. (Shanghai, China). Molybdenum disulfide $\left(\mathrm{MoS}_{2}\right)$ was obtained from Jiangsu XFNANO Materials Tech Co., Ltd. (Nanjing, China). Photoinitiator 2960 (99\%) was obtained from Shanghai Yinchang New Material Co., Ltd. (Shanghai, China). N,N'-Methylenebisacrylamide (MBA, 98\%) was purchased from J\&K Scientific Ltd. (Beijing, China). Methylene blue (MB) was purchased from Sinopharm Chemical Reagent Co., Ltd. All reagents were of analytical grade, and the water used in all experiments was deionized water.

Preparation of P(NIPAM-co-AAC) and P(NIPAM-coAAc)/MoS ${ }_{2}$ Composite Hydrogels. NIPAM (1 g) and $0.1 \mathrm{~g}$ of AAc were weighed and dissolved in an appropriate amount of deionized water. MBA $(2.72 \mathrm{mg})$ and $20 \mathrm{mg}$ of photoinitiator 2960 were added to the previous solution, and the mixture was shaken until an aqueous solution was obtained. A certain amount of $\mathrm{MoS}_{2}$ required was added to the deionized water and then mixed in an ultrasonic cell pulverizer for $30 \mathrm{~min}$. The $\mathrm{MoS}_{2}$ dispersion was combined with the solution containing monomers, cross-linker, and initiator and placed in an ice-water bath. The reaction was allowed to take place in a $365 \mathrm{~nm}$ low-pressure mercury lamp catalytic reaction device for $4 \mathrm{~h}$ under ultraviolet light irradiation. Changing the $\mathrm{MoS}_{2}$ mass from 0 to $25 \mathrm{mg}$, a series of $\mathrm{P}\left(\mathrm{NIPAM}-\mathrm{co}-\mathrm{AAc} / \mathrm{MoS}_{2}\right)$ composite hydrogels and the $\mathrm{P}$ (NIPAM-co-AAc) hydrogel without $\mathrm{MoS}_{2}$ can be prepared.

Characterization of Hydrogels. Fourier Transform Infrared Spectroscopy (FT-IR). The freeze-dried P(NIPAMco-AAc) and $\mathrm{P}$ (NIPAM-co-AAc) $/ \mathrm{MoS}_{2}$ hydrogel samples were ground into powder in a mortar and mixed with $\mathrm{KBr}$ to form tablets. Then, a Fourier infrared spectrometer (Nicolet, Avatar370) was used for the test.

Raman Spectroscopy (Raman). The freeze-dried P(NIPAM-co-AAc) and P(NIPAM-co-AAc)/ $\mathrm{MoS}_{2}$ hydrogel samples were ground into powder. A DXR Laser Raman 
microscope from Thermo Fisher Scientific (United States) was employed for testing. The laser wavelength of the Raman spectrometer used was $532 \mathrm{~nm}$.

Scanning Electron Microscope (SEM). The freeze-dried hydrogel sample was brittle fractured in liquid nitrogen, and then the cross section of the hydrogel was sprayed with gold. Then, the hydrogel was observed using the JSM-6360LA scanning electron microscope (JEOL Ltd., Japan).

Transmission Electron Microscope (TEM). The ethanol dispersion of $\mathrm{MoS}_{2}$ particles was dropped onto a copper mesh, and its morphology and size were observed with a Japanese JEOL JEM-2100 transmission electron microscope at an accelerating voltage of $200 \mathrm{kV}$.

$\zeta$-Potential Analysis. The low-concentration $\mathrm{MoS}_{2}$ dispersion was sonicated for $30 \mathrm{~min}$. The $\zeta$-potential of $\mathrm{MoS}_{2}$ particles in aqueous solutions was measured at $25{ }^{\circ} \mathrm{C}$ with a Malvern Zetasizer Nano ZS.

Swelling Ratio. At room temperature, $10 \mathrm{mg}$ of the freezedried P(NIPAM-co-AAc) and P(NIPAM-co-AAc)/ $/ \mathrm{MoS}_{2}$ composite hydrogel samples were added into $50 \mathrm{~mL}$ of water. The sample was taken out of the water at regular intervals, and the surface water was wiped with filter paper; its mass was weighed with a precision electronic balance. Equation 7 was used to calculate the swelling ratio WSR $(\mathrm{g} / \mathrm{g})$ of the hydrogel.

$$
\mathrm{WSR}=\frac{W_{t}-W_{0}}{W_{0}}
$$

where $W_{0}$ and $W_{t}$ represent the initial dried sample weight and the weight of the swollen sample at time $t$, respectively.

Dye Adsorption Experiment. Drawing the Standard Curve. First, $100 \mathrm{~mL}$ of $\mathrm{MB}$ solution at a concentration of $640 \mathrm{mg} / \mathrm{L}$ was prepared and then diluted with deionized water to different concentrations $(64,32,16,6.4,3.2,1.6,0.8$, and $0.64 \mathrm{mg} / \mathrm{L}$ ). A UV-vis spectrophotometer (UV-1800, Shimadzu Corporation, Japan) was used to measure the absorbance at a wavelength of $664 \mathrm{~nm}$. A standard curve (absorbance vs MB concentration) was created. The value for the unknown sample was determined by comparing it with the standard curve.

Adsorption Process. First, $100 \mathrm{~mL}$ of $\mathrm{MB}$ solution at a concentration of $640 \mathrm{mg} / \mathrm{L}$ was prepared and diluted with deionized water to different concentrations for adsorption experiments. The freeze-dried hydrogel samples were added into a series of prepared MB solutions with different concentrations to perform dye adsorption experiments at room temperature or $40{ }^{\circ} \mathrm{C}$. The absorbance of the solution was measured at regular intervals; its concentration was obtained from the standard curve, and the corresponding adsorption capacity was calculated according to eq 8

$$
Q_{t}=\frac{V\left(C_{0}-C_{t}\right)}{W_{0}}
$$

where $Q_{t}(\mathrm{mg} / \mathrm{g}), C_{0}(\mathrm{mg} / \mathrm{L}), C_{t}(\mathrm{mg} / \mathrm{L}), V(\mathrm{~L})$, and $W_{0}(\mathrm{~g})$ represent the adsorption capacity at time $t$, the initial $\mathrm{MB}$ concentration, residual $\mathrm{MB}$ concentration at time $t$, the volume of $\mathrm{MB}$ solution, and the weight of the dried hydrogel sample.

Similarly, to study the effect of the initial dye solution concentration on adsorption, the adsorption equilibrium of the MB dye on the hydrogel was studied at a concentration of $6.4-640.0 \mathrm{mg} / \mathrm{L}$ at room temperature and $40{ }^{\circ} \mathrm{C}$.

\section{ASSOCIATED CONTENT}

\section{(s) Supporting Information}

The Supporting Information is available free of charge at https://pubs.acs.org/doi/10.1021/acsomega.1c04433.

Thermogravimetric analysis of hydrogels; coefficients of the KASRA equation; and adsorption kinetic KASRA model (PDF)

\section{AUTHOR INFORMATION}

\section{Corresponding Authors}

Jianping Yang - Department of Orthopedics, Changzhou Hospital of Traditional Chinese Medicine, Changzhou 213000 Jiangsu, P. R. China; Email: 43655304@qq.com

Zheng Cao - Jiangsu Key Laboratory of Environmentally Friendly Polymeric Materials, School of Materials Science and Engineering, Jiangsu Collaborative Innovation Center of Photovoltaic Science and Engineering, Changzhou University, Changzhou 213164 Jiangsu, P. R. China; Changzhou University Huaide College, Jingjiang 214500, P. R. China; National Experimental Demonstration Center for Materials Science and Engineering, Changzhou University, Changzhou 213164, P. R. China; (1) orcid.org/0000-0003-2018-1569; Email: zcao@cczu.edu.cn, caozheng0571@hotmail.com

\section{Authors}

Kailun Wang - Jiangsu Key Laboratory of Environmentally Friendly Polymeric Materials, School of Materials Science and Engineering, Jiangsu Collaborative Innovation Center of Photovoltaic Science and Engineering, Changzhou University, Changzhou 213164 Jiangsu, P. R. China

Zhengxiang Lv - Department of Orthopedics, Changzhou Hospital of Traditional Chinese Medicine, Changzhou 213000 Jiangsu, P. R. China

Wenjun Li - Jiangsu Key Laboratory of Environmentally Friendly Polymeric Materials, School of Materials Science and Engineering, Jiangsu Collaborative Innovation Center of Photovoltaic Science and Engineering, Changzhou University, Changzhou 213164 Jiangsu, P. R. China

Keming Luo - Jiangsu Key Laboratory of Environmentally Friendly Polymeric Materials, School of Materials Science and Engineering, Jiangsu Collaborative Innovation Center of Photovoltaic Science and Engineering, Changzhou University, Changzhou 213164 Jiangsu, P. R. China

Complete contact information is available at:

https://pubs.acs.org/10.1021/acsomega.1c04433

\section{Notes}

The authors declare no competing financial interest.

\section{ACKNOWLEDGMENTS}

This project was supported by the National Natural Science Foundation of China (Grant No. 21704008), Major Science and Technology Project of Changzhou Health Commission (Project No: ZD201917), Natural Science Foundation of Jiangsu Province, China (Grant No. BK20201449), and Natural Science Foundation of the Jiangsu Higher Institutions of China (Grant No. 20KJA430011). Financial support provided for this project by the Priority Academic Program Development of Jiangsu Higher Education Institutions (PAPD) and the Top-notch Academic Programs Project of Jiangsu Higher Education Institutions (TAPP), and financial support from the Young Elite Scientist Sponsorship Program of 
the Jiangsu Province Association of Science and Technology, Postgraduate Research \& Practice Innovation Program of Jiangsu Province are also gratefully acknowledged.

\section{REFERENCES}

(1) Yagub, M. T.; Sen, T. K.; Afroze, S.; Ang, H. M. Dye and its removal from aqueous solution by adsorption: A review. Adv. Colloid Interface Sci. 2014, 209, 172-184.

(2) Katheresan, V.; Kansedo, J.; Lau, S. Y. Efficiency of various recent wastewater dye removal methods: A review. J. Environ. Chem. Eng. 2018, 6, 4676-4697.

(3) Ahmad, A.; Mohd-Setapar, S. H.; Chuong, C. S.; Khatoon, A.; Wani, W. A.; Kumar, R.; Rafatullah, M. Recent advances in new generation dye removal technologies: novel search for approaches to reprocess wastewater. RSC Adv. 2015, 5, 30801-30818.

(4) Maruthapandi, M.; Kumar, V. B.; Gedanken, A. Carbon Dot Initiated Synthesis of Poly(4,4'-diaminodiphenylmethane) and Its Methylene Blue Adsorption. ACS Omega 2018, 3, 7061-7068.

(5) Cao, Z.; Gordiichuk, P. I.; Loos, K.; Sudhölter, E. J. R.; de Smet, L. C. P. M. The effect of guanidinium functionalization on the structural properties and anion affinity of polyelectrolyte multilayers. Soft Matter 2016, 12, 1496-1505.

(6) Maruthapandi, M.; Kumar, V. B.; Luong, J. H. T.; Gedanken, A. Kinetics, Isotherm, and Thermodynamic Studies of Methylene Blue Adsorption on Polyaniline and Polypyrrole Macro-Nanoparticles Synthesized by C-Dot-Initiated Polymerization. ACS Omega 2018, 3, 7196-7203.

(7) Feng, M.; You, W.; Wu, Z.; Chen, Q.; Zhan, H. Mildly Alkaline Preparation and Methylene Blue Adsorption Capacity of Hierarchical Flower-like Sodium Titanate. ACS Appl. Mater. Interfaces 2013, 5, 12654-12662.

(8) Li, Q.; Qiao, X.-Q.; Jia, Y.; Hou, D.; Li, D.-S. Amorphous CoMoS4 Nanostructure for Photocatalytic H2 Generation, Nitrophenol Reduction, and Methylene Blue Adsorption. ACS Appl. Nano Mater. 2020, 3, 68-76.

(9) Gui, C.-X.; Wang, Q.-Q.; Hao, S.-M.; Qu, J.; Huang, P.-P.; Cao, C.-Y.; Song, W.-G.; Yu, Z.-Z. Sandwichlike Magnesium Silicate/ Reduced Graphene Oxide Nanocomposite for Enhanced $\mathrm{Pb} 2+$ and Methylene Blue Adsorption. ACS Appl. Mater. Interfaces 2014, 6, 14653-14659.

(10) Li, Y.; Pan, C.; Kamdem, P.; Jin, X.-J. Binder-Free TwoDimensional MXene/Acid Activated Carbon for High-Performance Supercapacitors and Methylene Blue Adsorption. Energy Fuels 2020, 34, 10120-10130.

(11) Ortega, P. F. R.; Trigueiro, J. P. C.; Santos, M. R.; Denadai, Â. M. L.; Oliveira, L. C. A.; Teixeira, A. P. C.; Silva, G. G.; Lavall, R. L. Thermodynamic Study of Methylene Blue Adsorption on Carbon Nanotubes Using Isothermal Titration Calorimetry: A Simple and Rigorous Approach. J. Chem. Eng. Data 2017, 62, 729-737.

(12) Ramos, J.; Imaz, A.; Forcada, J. Temperature-sensitive nanogels: poly $(\mathrm{N}$-vinylcaprolactam $)$ versus poly $(\mathrm{N}$-isopropylacrylamide). Polym. Chem. 2012, 3, 852-856.

(13) Wiedemair, J.; Serpe, M. J.; Kim, J.; Masson, J.-F.; Lyon, L. A.; Mizaikoff, B.; Kranz, C. In-Situ AFM Studies of the Phase-Transition Behavior of Single Thermoresponsive Hydrogel Particles. Langmuir 2007, 23, 130-137.

(14) Cao, Z.; Du, B.; Chen, T.; Li, H.; Xu, J.; Fan, Z. Fabrication and Properties of Thermosensitive Organic/Inorganic Hybrid Hydrogel Thin Films. Langmuir 2008, 24, 5543-5551.

(15) Schmidt, S.; Hellweg, T.; von Klitzing, R. Packing Density Control in $\mathrm{P}$ (NIPAM-co-AAc) Microgel Monolayers: Effect of Surface Charge, $\mathrm{pH}$, and Preparation Technique. Langmuir 2008, 24, 12595-12602.

(16) Xia, L.-W.; Ju, X.-J.; Liu, J.-J.; Xie, R.; Chu, L.-Y. Responsive hydrogels with poly(N-isopropylacrylamide-co-acrylic acid) colloidal spheres as building blocks. J. Colloid Interface Sci. 2010, 349, 106113.
(17) Zhang, J.; Chu, L.-Y.; Li, Y.-K.; Lee, Y. M. Dual thermo- and $\mathrm{pH}$-sensitive poly(N-isopropylacrylamide-co-acrylic acid) hydrogels with rapid response behaviors. Polymer 2007, 48, 1718-1728.

(18) Boztepe, C.; Künkül, A.; Yüceer, M. Application of artificial intelligence in modeling of the doxorubicin release behavior of $\mathrm{pH}$ and temperature responsive poly(NIPAAm-co-AAc)-PEG IPN hydrogel. J. Drug Delivery Sci. Technol. 2020, 57, No. 101603.

(19) Zhang, M.; Li, Y.; Yang, Q.; Huang, L.; Chen, L.; Ni, Y.; Xiao, $\mathrm{H}$. Temperature and $\mathrm{pH}$ responsive cellulose filament/poly (NIPAMco-AAc) hybrids as novel adsorbent towards $\mathrm{Pb}(\mathrm{II})$ removal. Carbohydr. Polym. 2018, 195, 495-504.

(20) Cao, Z.; Chen, T.-y.; Guo, X.-1.; Zhou, X.-j.; Nie, J.-j.; Xu, J.-t.; Fan, Z.-q.; Du, B.-y. Synthesis and properties of organic-inorganic hybrid P(NIPAM-co-AM-co-TMSPMA) microgels. Chin. J. Polym. Sci. 2011, 29, 439-449.

(21) Kureha, T.; Shibamoto, T.; Matsui, S.; Sato, T.; Suzuki, D. Investigation of Changes in the Microscopic Structure of Anionic Poly(N-isopropylacrylamide-co-Acrylic acid) Microgels in the Presence of Cationic Organic Dyes toward Precisely Controlled Uptake/ Release of Low-Molecular-Weight Chemical Compound. Langmuir 2016, 32, 4575-4585.

(22) Naseem, K.; Begum, R.; Wu, W.; Usman, M.; Irfan, A.; AlSehemi, A. G.; Farooqi, Z. H. Adsorptive removal of heavy metal ions using polystyrene-poly( $\mathrm{N}$-isopropylmethacrylamide-acrylic acid) core/shell gel particles: Adsorption isotherms and kinetic study. $J$. Mol. Liq. 2019, 277, 522-531.

(23) Cao, Z.; Guo, J.; Fan, X.; Xu, J.; Fan, Z.; Du, B. Detection of heavy metal ions in aqueous solution by $\mathrm{P}(\mathrm{MBTVBC}-\mathrm{co}-\mathrm{VIM})$ coated QCM sensor. Sens. Actuators, B 2011, 157, 34-41.

(24) Jiang, C.; Ma, X.; Xue, M.; Lian, H.-z. Application of thermoresponsive hydrogel/gold nanorods composites in the detection of diquat. Talanta 2017, 174, 192-197.

(25) Parasuraman, D.; Serpe, M. J. Poly (N-Isopropylacrylamide) Microgels for Organic Dye Removal from Water. ACS Appl. Mater. Interfaces 2011, 3, 2732-2737.

(26) Wang, L.; Geng, J.; Bai, B. Highly Deformable Nano-CrossLinker-Bridged Nanocomposite Hydrogels for Water Management of Oil Recovery. Energy Fuels 2018, 32, 3068-3076.

(27) Cao, Z.; Chen, Y.; Zhang, C.; Cheng, J.; Wu, D.; Ma, W.; Liu, C.; $\mathrm{Fu}, \mathrm{Z}$. Preparation of near-infrared laser responsive hydrogels with enhanced laser marking performance. Soft Matter 2019, 15, 29502959.

(28) Zhang, C.; Dai, Y.; Wu, Y.; Lu, G.; Cao, Z.; Cheng, J.; Wang, K.; Yang, H.; Xia, Y.; Wen, X.; Ma, W.; Liu, C.; Wang, Z. Facile preparation of polyacrylamide/chitosan/ $\mathrm{Fe} 3 \mathrm{O} 4$ composite hydrogels for effective removal of methylene blue from aqueous solution. Carbohydr. Polym. 2020, 234, No. 115882.

(29) Na, Y.-H.; Kurokawa, T.; Katsuyama, Y.; Tsukeshiba, H.; Gong, J. P.; Osada, Y.; Okabe, S.; Karino, T.; Shibayama, M. Structural Characteristics of Double Network Gels with Extremely High Mechanical Strength. Macromolecules 2004, 37, 5370-5374.

(30) Cao, Z.; Zhang, Y.; Luo, K.; Wu, Y.; Gao, H.; Cheng, J.; Liu, C.; Tao, G.; Guan, Q.; Zhang, L. Preparation and Properties of Polyacrylamide/Sodium Alginate Hydrogel and the Effect of $\mathrm{Fe}$ Adsorption on Its Mechanical Performance. J. Renewable Mater. 2021, 9, 1447-1462.

(31) Cao, Z.; Chen, Y.; Li, D.; Cheng, J.; Liu, C. Fabrication of Phosphate-Imprinted PNIPAM/SiO2 Hybrid Particles and Their Phosphate Binding Property. Polymers 2019, 11, No. 253.

(32) Liu, G.; Chunlin, L.; Yuyuan, C.; Shuai, Q.; Suyuan, Y.; Dun, W.; Haitao, X.; Zheng, C. Formation of the Self-assembled Multilayers Containing the Temperature/pH Dual-responsive Microgels. Nanosci. Nanotechnol. 2019, 9, 267-277.

(33) Cao, Z.; Hu, Y.; Yu, Q.; Lu, Y.; Wu, D.; Zhou, A.; Ma, W.; Xia, Y.; Liu, C.; Loos, K. Facile Fabrication, Structures, and Properties of Laser-Marked Polyacrylamide/Bi2O3 Hydrogels. Adv. Eng. Mater. 2017, 19, No. 1600826. 
(34) Cao, Z.; Chen, Y.; Zhang, Q.; Xia, Y.; Liu, G.; Wu, D.; Ma, W.; Cheng, J.; Liu, C. Preparation and ion sensing property of the selfassembled microgels by QCM. Nanofabrication 2017, 3, 16-25.

(35) Cao, Z.; Du, B.; Chen, T.; Nie, J.; Xu, J.; Fan, Z. Preparation and Properties of Thermo-sensitive Organic/Inorganic Hybrid Microgels. Langmuir 2008, 24, 12771-12778.

(36) Tang, L.; Wang, J.-j.; Wang, L.; Jia, C.-t.; Lv, G.-X.; Liu, N.; Wu, M.-h. Facile Synthesis of Silver Bromide-Based Nanomaterials and Their Efficient and Rapid Selective Adsorption Mechanisms Toward Anionic Dyes. ACS Sustainable Chem. Eng. 2016, 4, 4617-4625.

(37) Guan, Y.-F.; Marcos-Hernández, M.; Lu, X.; Cheng, W.; Yu, H.Q.; Elimelech, M.; Villagrán, D. Silica Removal Using Magnetic IronAluminum Hybrid Nanomaterials: Measurements, Adsorption Mechanisms, and Implications for Silica Scaling in Reverse Osmosis. Environ. Sci. Technol. 2019, 53, 13302-13311.

(38) Yu, Y.; Shi, Y.; Zhang, B. Synergetic Transformation of Solid Inorganic-Organic Hybrids into Advanced Nanomaterials for Catalytic Water Splitting. Acc. Chem. Res. 2018, 51, 1711-1721.

(39) Narula, A.; Rao, C. P. Hydrogel of the Supramolecular Complex of Graphene Oxide and Sulfonatocalix[4]arene as Reusable Material for the Degradation of Organic Dyes: Demonstration of Adsorption and Degradation by Spectroscopy and Microscopy. ACS Omega 2019, 4, 5731-5740.

(40) Moztahida, M.; Lee, D. S. Photocatalytic degradation of methylene blue with P25/graphene/polyacrylamide hydrogels: Optimization using response surface methodology. J. Hazard. Mater. 2020, 400, No. 123314.

(41) Jv, X.; Zhao, X.; Ge, H.; Sun, J.; Li, H.; Wang, Q.; Lu, H. Fabrication of a Magnetic Poly(aspartic acid)-Poly(acrylic acid) Hydrogel: Application for the Adsorptive Removal of Organic Dyes from Aqueous Solution. J. Chem. Eng. Data 2019, 64, 1228-1236.

(42) Singh, N.; Riyajuddin, S.; Ghosh, K.; Mehta, S. K.; Dan, A. Chitosan-Graphene Oxide Hydrogels with Embedded Magnetic Iron Oxide Nanoparticles for Dye Removal. ACS Appl. Nano Mater. 2019, 2, 7379-7392.

(43) Basu, H.; Singh, S.; Venkatesh, M.; Pimple, M. V.; Singhal, R. $\mathrm{K}$. Graphene oxide-MnO2-goethite microsphere impregnated alginate: A novel hybrid nanosorbent for As (III) and As (V) removal from groundwater. J. Water Process Eng. 2021, 42, No. 102129.

(44) Wang, X.-1.; Qin, W.; Wang, L.-x.; Zhao, K.-y.; Wang, H.-c.; Liu, H.-y.; Wei, J.-f. Desalination of dye utilizing carboxylated TiO2/ calcium alginate hydrogel nanofiltration membrane with high salt permeation. Sep. Purif. Technol. 2020, 253, No. 117475.

(45) Zhou, J.; Hao, B.; Wang, L.; Ma, J.; Cheng, W. Preparation and characterization of nano-TiO2/chitosan/poly $(\mathrm{N}$-isopropylacrylamide) composite hydrogel and its application for removal of ionic dyes. Sep. Purif. Technol. 2017, 176, 193-199.

(46) Jiang, H.; Carter, N. M.; Zareei, A.; Nejati, S.; Waimin, J. F.; Chittiboyina, S.; Niedert, E. E.; Soleimani, T.; Lelièvre, S. A.; Goergen, C. J.; Rahimi, R. A Wireless Implantable Strain Sensing Scheme Using Ultrasound Imaging of Highly Stretchable Zinc Oxide/ Poly Dimethylacrylamide Nanocomposite Hydrogel. ACS Appl. Bio Mater. 2020, 3, 4012-4024.

(47) Zhao, Y.; Zhang, Y.; Liu, A.; Wei, Z.; Liu, S. Construction of Three-Dimensional Hemin-Functionalized Graphene Hydrogel with High Mechanical Stability and Adsorption Capacity for Enhancing Photodegradation of Methylene Blue. ACS Appl. Mater. Interfaces 2017, 9, 4006-4014.

(48) Gopalakrishnan, D.; Damien, D.; Shaijumon, M. M. MoS2 Quantum Dot-Interspersed Exfoliated MoS2 Nanosheets. ACS Nano 2014, 8, 5297-5303.

(49) Park, H.; Liu, N.; Kim, B. H.; Kwon, S. H.; Baek, S.; Kim, S.; Lee, H.-K.; Yoon, Y. J.; Kim, S. Exceptionally Uniform and Scalable Multilayer MoS2 Phototransistor Array Based on Large-Scale MoS2 Grown by RF Sputtering, Electron Beam Irradiation, and Sulfurization. ACS Appl. Mater. Interfaces 2020, 12, 20645-20652.

(50) Kwak, J. Y.; Hwang, J.; Calderon, B.; Alsalman, H.; Munoz, N.; Schutter, B.; Spencer, M. G. Electrical Characteristics of Multilayer
MoS2 FET's with MoS2/Graphene Heterojunction Contacts. Nano Lett. 2014, 14, 4511-4516.

(51) Cao, Z.; Lu, G.; Gao, H.; Xue, Z.; Luo, K.; Wang, K.; Cheng, J.; Guan, Q.; Liu, C.; Luo, M. Preparation and Laser Marking Properties of Poly(propylene)/Molybdenum Sulfide Composite Materials. ACS Omega 2021, 6, 9129-9140.

(52) Schneider, R.; Facure, M. H. M.; Alvarenga, A. D.; Chagas, P. A. M.; dos Santos, D. M.; Correa, D. S. Dye Adsorption Capacity of MoS2 Nanoflakes Immobilized on Poly(lactic acid) Fibrous Membranes. ACS Appl. Nano Mater. 2021, 4, 4881-4894.

(53) Tian, C.; Xiang, X.; Wu, J.; Li, B.; Cai, C.; Khan, B.; Chen, H.; Yuan, Y.; Zu, X. Facile Synthesis of MoS2/CuS Nanosheet Composites as an Efficient and Ultrafast Adsorbent for Water-Soluble Dyes. J. Chem. Eng. Data 2018, 63, 3966-3974.

(54) Chiu, D.-J.; Li, Y.; Feng, C.-K.; Yang, M.-R.; Chen, K.-S.; Swieszkowski, W. Preparation and enhanced mechanical properties of hydroxyapatite hybrid hydrogels via novel photocatalytic polymerization. J. Polym. Res. 2017, 24, No. 227.

(55) Tanabe, T.; Osaki, J.; Miyajima, M.; Kitamura, K.; Oyama, Y. Raman and TEM characterization of 2D layered MoS2 crystals grown on non-metal surfaces by friction-induced synthesis. Appl. Surf. Sci. 2021, 561, No. 150016.

(56) Hou, N.; Wang, R.; Wang, F.; Bai, J.; Zhou, J.; Zhang, L.; Hu, J.; Liu, S.; Jiao, T. Fabrication of Hydrogels via Host-Guest Polymers as Highly Efficient Organic Dye Adsorbents for Wastewater Treatment. ACS Omega 2020, 5, 5470-5479.

(57) Rafi, M.; Samiey, B.; Cheng, C.-H. Study of Adsorption Mechanism of Congo Red on Graphene Oxide/PAMAM Nanocomposite. Materials. 2018, 11, No. 496.

(58) Fu, J.; Chen, Z.; Wang, M.; Liu, S.; Zhang, J.; Zhang, J.; Han, $\mathrm{R}$; $\mathrm{Xu}, \mathrm{Q}$. Adsorption of methylene blue by a high-efficiency adsorbent (polydopamine microspheres): Kinetics, isotherm, thermodynamics and mechanism analysis. Chem. Eng. J. 2015, 259, 53-61.

(59) Bello, K.; Sarojini, B. K.; Narayana, B.; Rao, A.; Byrappa, K. A study on adsorption behavior of newly synthesized banana pseudostem derived superabsorbent hydrogels for cationic and anionic dye removal from effluents. Carbohydr. Polym. 2018, 181, 605-615.

(60) Marrakchi, F.; Auta, M.; Khanday, W. A.; Hameed, B. H. Highsurface-area and nitrogen-rich mesoporous carbon material from fishery waste for effective adsorption of methylene blue. Powder Technol. 2017, 321, 428-434.

(61) Wan, X.; Zhan, Y.; Long, Z.; Zeng, G.; He, Y. Core@doubleshell structured magnetic halloysite nanotube nano-hybrid as efficient recyclable adsorbent for methylene blue removal. Chem. Eng. J. 2017, 330, 491-504.

(62) Gao, B.; Yu, H.; Wen, J.; Zeng, H.; Liang, T.; Zuo, F.; Cheng, C. Super-adsorbent poly(acrylic acid)/laponite hydrogel with ultrahigh mechanical property for adsorption of methylene blue. J. Environ. Chem. Eng. 2021, 9, No. 106346.

(63) Tang, Z.; Hu, X.; Ding, H.; Li, Z.; Liang, R.; Sun, G. Villi-like poly(acrylic acid) based hydrogel adsorbent with fast and highly efficient methylene blue removing ability. J. Colloid Interface Sci. 2021, 594, 54-63.

(64) Liu, J.; Liu, G.; Liu, W. Preparation of water-soluble $\beta$ cyclodextrin/poly(acrylic acid)/graphene oxide nanocomposites as new adsorbents to remove cationic dyes from aqueous solutions. Chem. Eng. J. 2014, 257, 299-308.

(65) Mohammed, N.; Grishkewich, N.; Waeijen, H. A.; Berry, R. M.; Tam, K. C. Continuous flow adsorption of methylene blue by cellulose nanocrystal-alginate hydrogel beads in fixed bed columns. Carbohydr. Polym. 2016, 136, 1194-1202. 